\title{
Initial experience with excimer laser angioplasty for coronary ostial stenoses
}

\author{
Clive S Lawson, Ian C Cooper, Michael M Webb-Peploe
}

\begin{abstract}
The excimer laser has several potential advantages over conventional balloon angioplasty in the management of stenoses of the native coronary arteries and of the ostia of saphenous vein grafts. Its use in nine patients, eight of whom were classed as high risk, is described. Four lesions involved the ostia of saphenous vein grafts, three of protected left main stems, and two of native right coronary arteries. Stand alone laser was used in seven cases and laser with additional balloon angioplasty was used in two vein graft stenoses. Acute laser success was achieved in all cases, with a mean reduction of stenosis from $82 \%$ to $34 \%$ after laser alone and to $28 \%$ when balloon angioplasty was used as well. One patient died during laser angioplasty to a nonostial lesion (procedural success rate $89 \%$ ) and a second died ten weeks after the procedure. In one patient recurrent angina developed (clinical recurrence rate $25 \%$ ) and restenosis was confirmed on angiography. Follow up angiography was also performed on the other six surviving patients, all of whom were symptom free and none of whom showed evidence of significant restenosis (restenosis rate $14 \%$ ). With a mean follow up of 19.7 months the overall success rate was $67 \%$.
\end{abstract}

\section{(Br Heart J 1993;69:255-259)}

The results of conventional balloon angioplasty for coronary ostial stenoses are significantly worse than those for non-ostial lesions. Low rates for procedural success and high rates for acute complications and restenosis have been reported. ${ }^{12}$ These may be explained by technical difficulties encountered during the procedure. It has been suggested that ostial lesions may have an atypical composition ${ }^{3}$ which could also contribute to these poor results.

Use of the excimer laser might overcome some of these limitations. We report the clinical and procedural details and angiographic follow up of nine patients in whom coronary ostial stenoses were successfully dilated by eximer laser angioplasty.

\section{Patients and methods}

PATIENTS

Between February 1990 and March 1991 nine patients underwent excimer laser coronary angioplasty to ostial stenoses of native coronary artery and saphenous vein grafts at St Thomas' Hospital, London. Table 1 summarises the demographic and clinical data on these patients. Eight patients were considered to be at high risk: a left ventricular ejection fraction below $35 \%$ (patent 9 ), compromised flow in all major native coronary arteries and coronary grafts (patients $1,3,4,5$ ), treatment of a sole remaining patient conduit (patient 3 ), surgical backup having been refused on clinical grounds (patients 2, 3, 5, and 9), or unstable angina in patients who were dependent on intravenous nitrate (patients 2, 5, 6, and 7). None had known syphilitic or Takayashu's aortitis and none had received previous mediastinal radiotherapy. All patients gave informed consent to the procedures.

\section{DEFINITIONS}

Ostial stenosis was defined as a lesion producing $>50 \%$ diameter reduction within $0.3 \mathrm{~cm}$ of the vessel orifice. Acute laser success, procedural success, and restenosis were defined according to the Excimer Laser Coronary

Table 1 Demographic and clinical details

\begin{tabular}{|c|c|c|c|c|c|c|c|c|c|c|c|}
\hline $\begin{array}{l}\text { Case } \\
\text { No. }\end{array}$ & $\begin{array}{l}\text { Age } \\
(y r)\end{array}$ & Sex & $\begin{array}{l}1,2, \text { or } 3 \\
\text { vessel } \\
\text { disease }\end{array}$ & $\begin{array}{l}\text { Previous } \\
\text { operation }\end{array}$ & $\begin{array}{l}\text { Further } \\
\text { operation } \\
\text { refused }^{\star}\end{array}$ & $\begin{array}{l}\text { Previous } \\
\text { PTCA to } \\
\text { lesion }\end{array}$ & $\begin{array}{l}\text { Smoking } \\
\text { history }\end{array}$ & $\begin{array}{l}\text { Hyper- } \\
\text { cholesterolaemia } \dagger\end{array}$ & $H T$ & Diabetes & CCS class \\
\hline $\begin{array}{l}1 \\
2 \\
3 \\
4 \\
5 \\
6 \\
7 \\
8 \\
9\end{array}$ & $\begin{array}{l}63 \\
63 \\
49 \\
57 \\
47 \\
54 \\
65 \\
54 \\
58\end{array}$ & $\begin{array}{l}F \\
M \\
F \\
M \\
M \\
M \\
M \\
F \\
F\end{array}$ & $\begin{array}{l}2 \\
3 \\
3 \\
3 \\
3 \\
2 \\
3 \\
1 \\
3\end{array}$ & $\begin{array}{l}\text { CABG } \\
\text { CABG } \\
\text { CABG (2) } \\
\text { CABG } \\
\text { CABG (2) } \\
\text { AVR } \\
\text { CABG } \\
\text { No } \\
\text { CABG }\end{array}$ & $\begin{array}{l}\text { No } \\
\text { Yes } \\
\text { Yes } \\
\text { No } \\
\text { Yes } \\
\text { No } \\
\text { No } \\
\text { N/A } \\
\text { Yes }\end{array}$ & $\begin{array}{l}\text { No } \\
\text { No } \\
\text { No } \\
\text { No } \\
\text { No } \\
\text { No } \\
\text { No } \\
\text { No } \\
\text { Yes (2) }\end{array}$ & $\begin{array}{l}\text { Ex } \\
\text { Ex } \\
\text { Ex } \\
\text { Yes } \\
\text { No } \\
\text { No } \\
\text { No } \\
\text { No } \\
\text { No }\end{array}$ & $\begin{array}{l}\text { Yes } \\
\text { No } \\
\text { No } \\
\text { No } \\
\text { Yes } \\
\text { No } \\
\text { No } \\
\text { No } \\
\text { Yes }\end{array}$ & $\begin{array}{l}\text { Yes } \\
\text { No } \\
\text { Yes } \\
\text { No } \\
\text { No } \\
\text { No } \\
\text { No } \\
\text { No } \\
\text { No }\end{array}$ & $\begin{array}{l}\text { No } \\
\text { No } \\
\text { No } \\
\text { No } \\
\text { Yes } \\
\text { No } \\
\text { No } \\
\text { No } \\
\text { No }\end{array}$ & $\begin{array}{l}3 \\
4 \\
3 \\
2 \\
4 \\
4 \\
4 \\
2 \\
3\end{array}$ \\
\hline
\end{tabular}

CABG, coronary artery bypass grafting; CABG (2), coronary artery bypass grafting on two occasions; AVR, aortic valve replacement; N/A, not applicable; PTCA, percutaneous transluminal coronary angioplasty; HT, hypertension requiring drug therapy; CCS class, Canadian Cardiovascular Society functional class. percutaneous transluminal coronary angioplasty; HT, hypertension requiring drug therap

†Fasting serum cholesterol $>6.5 \mathrm{mmol} / \mathrm{l}$ and resistant to dietary management. 
Table 2 Procedural details

\begin{tabular}{lllllll}
\hline Number & $\begin{array}{l}\text { Site of } \\
\text { lesion }\end{array}$ & $\begin{array}{l}\text { Guide } \\
\text { catheter }\end{array}$ & $\begin{array}{l}\text { Guide wire } \\
\text { (inch) }\end{array}$ & $\begin{array}{l}\text { Laser fibre } \\
\text { diameter }(\mathrm{mm})\end{array}$ & Passes & Balloon \\
\hline 1 & LMS & J-L & $0.018 \mathrm{HTF}$ & $2 \cdot 0$ & 2 & No \\
2 & SVG & A-L & $0.018 \mathrm{HTF}$ & $1 \cdot 3$ and 2.0 & 3 and 2 & No \\
3 & SVG & J-R & $0.018 \mathrm{HTF}$ & $2 \cdot 0$ & 3 & Yes \\
4 & SVG & A-L & $0.018 \mathrm{HTF}$ & $2 \cdot 0$ & No \\
5 & SVG & J-R & 0.018 HTF & $2 \cdot 0$ & 3 & Yes \\
6 & RCA & J-R & 0.018 HTF & $2 \cdot 0$ & No \\
7 & LMS & J-L & 0.018 HTF & $2 \cdot 0$ & 4 & No \\
8 & RCA & A-L & 0.021 Magnum & $2 \cdot 0$ & 2 & No \\
9 & LMS & A-L & 0.018 HTF & $1 \cdot 6$ and 2.0 & 4 and 2 & No \\
\hline
\end{tabular}

LMS, left main stem; SVG, saphenous vein graft; RCA, right coronary artery; J-L, Judkins type left; J-R, Judkins type right; A-L, Amplatz type left; HTF, high torque floppy.

Angioplasty Registry. ${ }^{4}$ Acute laser success was defined as an increase in the lumen diameter by $>20 \%$ (with a lumen of $>1.5 \mathrm{~mm}$ for a $2 \mathrm{~mm}$ fibre), procedural success as a residual stenosis of $\leqslant 50 \%$ after excimer laser angioplasty (with or without balloon angioplasty) without major complications and restenosis as $>50 \%$ narrowing at the site of a previously successful dilatation. Clinical recurrence was defined as the return of symptoms after initial improvement after a procedural success, and long-term success was defined as a procedural success without clinical recurrence or restenosis. Data are expressed as mean (SD) where appropriate.

\section{TECHNIQUES}

All procedures were performed via the femoral artery. All patients were given aspirin and a calcium antagonist. Heparin was administered to achieve an activated clotting time of $>400$ seconds before laser treatment. After the procedure all patients were given intravenous nitrates and heparin (1000 U/hour) for 12 hours. Table 2 summarises the procedural details. We used nine FG guide catheters with side holes in all cases.

Laser energy was generated by the xenon chloride excimer laser from Advanced Interventional Systems. This produces a 308 $\mathrm{nm}$ pulsed laser (pulse width $250 \mathrm{~ns}$ ) which was delivered by multifibre front-firing laser catheters. $2.0 \mathrm{~mm}$ laser fibres were used in all cases; this was preceded by passage of a $1.3 \mathrm{~mm}$ fibre in one case and a $1.6 \mathrm{~mm}$ fibre in one other. The delivered laser energies were $45-50 \mathrm{~mJ} / \mathrm{mm}^{2}$ for the 1.6 and $2.0 \mathrm{~mm}$ fibre and $50-60 \mathrm{~mJ} / \mathrm{mm}^{2}$ for the $1.3 \mathrm{~mm}$ fibre. The practical aspects of the passage of excimer laser angioplasty fibres have recently been reviewed. ${ }^{5}$ An over the wire technique was used in all cases. Several three second laser bursts separated by five second intervals were used during the passage of all laser fibres. The laser fibre was advanced at a rate of less than $1 \mathrm{~mm} / \mathrm{s}$ until it was at least 3 $\mathrm{mm}$ beyond the lesion. To achieve optimal results several passes were required in eight cases with the laser fibre directed at different aspects of the lesion or with an increase in the diameter of the fibre or both. The figure shows an example of the result of such a sequence of passes. A stand alone laser was used in seven cases. The other two patients required balloon $(3.5 \mathrm{~mm})$ supplementation for saphenous vein graft lesions.
The severity of coronary lesions was estimated visually from digitally subtracted angiograms (Siemens) in at least two perpendicular views and expressed as the percentage reduction in luminal diameter compared with the nearest "normal" arterial segment. This process was assisted by the use of commercial software for edge detection and stenosis quantification in all cases.

Late complications and functional status were ascertained. Repeat angiography was performed in seven patients with views identical to those used for the initial procedure. The figure shows a six month follow up angiogram after excimer laser angioplasty.

\section{Results}

Four lesions affected the ostia of saphenous vein grafts, three the ostia of protected left main stems, and two the ostia of native right coronary arteries. Table 3 summarises the individual results. Acute laser success was achieved in all cases. The mean (SD) reduction of stenosis was from $83(13) \%$ to $34(13) \%$ with laser alone and to 28 (9)\% after balloon supplementation

One patient (case 5) died 15 hours after the procedure. After successful excimer laser angioplasty to a vein graft ostial stenosis, attempted excimer laser angioplasty to a further lesion in the left anterior descending artery resulted in a local perforation. Tamponade did not occur as the pericardial space had been obliterated by two previous bypass graft procedures. The patient subsequently developed chest pain associated with anterior ST segment elevation followed by intractable ventricular fibrillation. A postmortem examination showed cholesterol embolisation in the distal left anterior descending artery, presumably secondary to rupture of a proximal lipid rich plaque. This may have been caused by laser ablation of the surface of the plaque although mechanical trauma cannot be excluded. There were no other major acute complications. Thus the procedural success rate for the nine cases was $89 \%$.

One patient (case 3), who had an ostial lesion in a vein graft that formed the sole remaining conduit, tolerated passage of the $2 \mathrm{~mm}$ laser fibre without problems. Inflation of a $3.5 \mathrm{~mm}$ balloon to dilate further the residual stenosis, however, caused severe chest pain and haemodynamic deterioration that limited the inflation time to 20 seconds. The patient 
Figure Serial digitally subtracted angiograms in the right anterior oblique view of the saphenous vein graft to the left anterior descending coronary artery in patient 4. ( $A) A$ severe eccentric ostial lesion before laser treatment. (B) Lesion after three passes of a $2 \mathrm{~mm}$ laser fibre. (C) Lesion at follow up after six months.

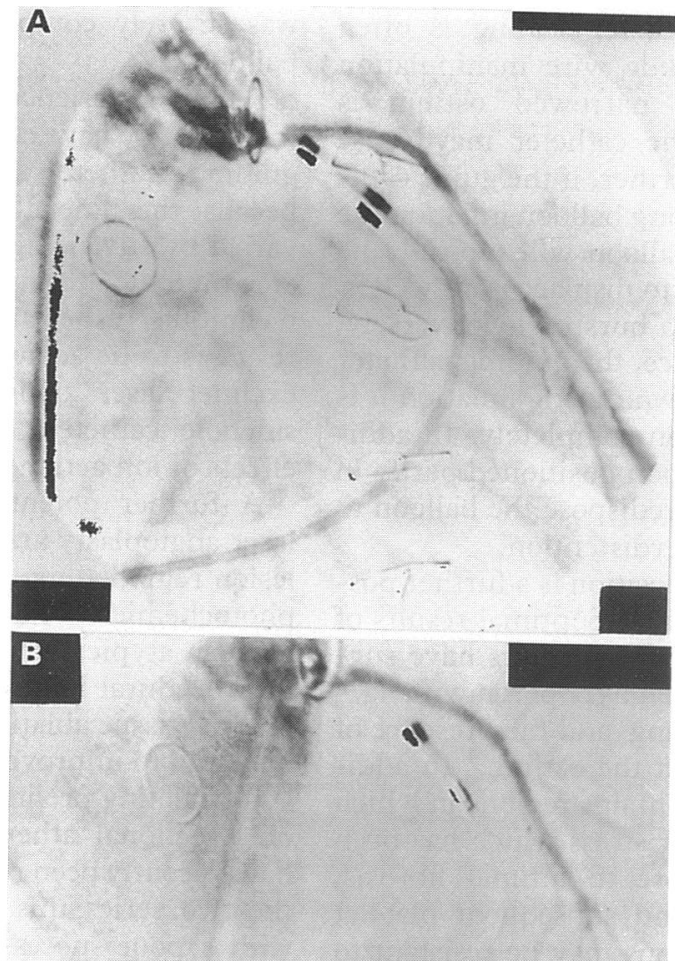

FOLLOW UP

The mean follow up was $19 \cdot 7(4 \cdot 2)$ months (table 3). A second patient (case 3, described above) died 10 weeks after an initially successful procedure. The patient was discharged free of symptoms having been initially admitted with at rest pain and remained symptom free until admission to another hospital with further chest pain at rest, widespread repolarisation changes, and subsequent cardiac arrest. A postmortem examination was not performed. There were no other late complications.

In one patient (case 2) recurrent angina developed six weeks after a successful excimer laser angioplasty to the left main stem. Restenosis was confirmed on angiography but the patient's angina was subsequently controlled by medical treatment. The remaining six patients remain free of clinical recurrence and none showed evidence of significant restenosis on follow up angiography. Maintenance of angiographic improvement was good (mean stenosis $39(15) \%$ from $29(9) \%)$. The mean time to angiographic follow up was $6.3(2.5)$ months. Functional improvement was also well maintained in the seven surviving patients (six were in Canadian Cardiovascular Society class 0 and one was in class 3 (the patient in whom restenosis developed).

\section{Discussion}

Conventional balloon angioplasty is well established as a safe and effective technique for the treatment of patients with symptomatic coronary artery disease, ${ }^{6}$ however, the results obtained with ostial lesions are much worse than those with non-ostial lesions. In the only substantial series of patients with aortocoronary lesions Topol et al described the results of balloon angioplasty in 53 patients with right coronary artery ostial stenoses. ${ }^{2}$ They reported low rates for procedural and long term success (79\% and $47 \%$ respectively) and high rates for procedural complications ( $9 \%$ requiring emergency bypass surgery), clinical recurrence $(48 \%)$, and restenosis $(38 \%)$ despite a favourable risk profile within their patient population. Mathias et al reported similar results for stenoses at the ostium of a coronary branch vessel. ${ }^{1}$ Preliminary results suggest that stenting of ostial lesions at the time of angioplasty may be associated with improved procedural success but without an improvement in the restenosis rate. ${ }^{7}$

These poor results may be explained in part by technical difficulties encountered during the

Table 3 Results and outcome

\begin{tabular}{|c|c|c|c|c|c|c|c|c|c|}
\hline Number & $\begin{array}{l}\text { Site of } \\
\text { lesion }\end{array}$ & $\begin{array}{l}\% \text { Stenosis } \\
\text { pre ELCA }\end{array}$ & $\begin{array}{l}\% \text { Stenosis } \\
\text { post ELCA }\end{array}$ & $\begin{array}{l}\% \text { Stenosis } \\
\text { post PTCA }\end{array}$ & $\begin{array}{l}\text { Acute } \\
\text { complications }\end{array}$ & $\begin{array}{l}\text { Long term } \\
\text { complications }\end{array}$ & $\begin{array}{l}\text { Symptomatic } \\
\text { recurrence }\end{array}$ & $\begin{array}{l}\text { Restenosis } \\
(\%)\end{array}$ & CCS class \\
\hline 1 & LMS & 80 & 40 & N/A & No & No & No & No (40) & 0 \\
\hline 2 & SVG & 90 & 20 & N/A & No & No & Yes & Yes (60) & 3 \\
\hline 3 & SVG & 90 & 55 & 40 & No & Died at 10 weeks & Yes & Not documented & $\mathrm{N} / \mathrm{A}$ \\
\hline 4 & SVG & 90 & 20 & $\mathrm{~N} / \mathrm{A}$ & No & No & No & No $(40)$ & 0 \\
\hline 5 & SVG & 95 & 50 & 25 & Died & $\mathrm{N} / \mathrm{A}$ & $\mathrm{N} / \mathrm{A}$ & $\mathbf{N} / \mathbf{A}$ & $\mathrm{N} / \mathrm{A}$ \\
\hline 6 & RCA & 80 & 40 & N/A & No & No & No & No $(40)$ & 0 \\
\hline 7 & LMS & 60 & 20 & $\mathrm{~N} / \mathrm{A}$ & No & No & No & No (10) & 0 \\
\hline 8 & RCA & 95 & 30 & $\mathrm{~N} / \mathrm{A}$ & No & No & No & No $(40)$ & 0 \\
\hline 9 & LMS & 70 & 30 & $\mathbf{N} / \mathbf{A}$ & No & No & No & No $(40)$ & 0 \\
\hline
\end{tabular}

LMS, left main stem; SVG, saphenous vein graft; RCA, right coronary artery; \% stenosis estimated visually from digitally subtracted angiograms assisted by commercial quantification software; ELCA, excimer laser coronary angioplasty; PTCA, percutaneous transluminal coronary angioplasty; N/A, not applicable; CCS commercial quantification software; ELCA, excimer lase
class, Canadian Cardiovascular Society functional class. 
procedures. Guide catheter seating is often inadequate making guide wire manipulation difficult, and if the narrowed ostium is adequately engaged the catheter may cause occlusion or injury. Further, if the guide catheter is left engaged during balloon inflation the proximal end of the balloon will typically lie within its tip and tend to displace it, as well as predisposing to balloon bursting. Conversely, if, as is common practice, the guiding catheter is deliberately withdrawn during inflation it is possible to lose position completely. In addition, inflation of a balloon positioned partly in the aorta could itself predispose the balloon to bursting because of overdistention.

Atypical lesion composition is a further possible explanation for the suboptimal results of balloon angioplasty. Some workers have suggested congenital arterial hypoplasia with agerelated intimal thickening ${ }^{8}$ and the presence of a muscular sphincter at the ostium. ${ }^{9}$ In addition, a vessel ostium contains regions in which there is high wall shear stress which has been suggested to predispose to intimal fibrosis, endothelial damage, and subsequent platelet deposition. ${ }^{10}$ Such lesions may be resistant to dilatation (typically high inflation pressures are required to "crack" ostial lesions ${ }^{2}$ ) and may show exaggerated elastic recoil with consequent procedural failure or restenosis.

Thus coronary artery bypass grafting has often been preferred to angioplasty for the treatment of ostial stenoses. While this may be appropriate in patients where ostial lesions occur in the setting of multivessel coronary disease or in the left main stem, others may have an isolated right coronary ostial lesion. In addition many patients require further intervention because symptoms recur after bypass grafting. If a catheter based procedure could be shown to be safe and effective in such cases it would be preferred to surgery.

The initial six months' results of excimer laser angioplasty for all cases from this centre have already been reported. ${ }^{11}$ For ostial lesions this technique offers several potential advantages that may overcome the limitations of balloon angioplasty. The major benefit is a reduction in the procedural difficulties described. While there is a tendency for the laser fibre to displace the guide catheter as it is advanced during the application of laser energy to the lesion, this can largely be overcome by slowly withdrawing the guide wire by $1-2 \mathrm{~cm}$ during each short burst of laser energy and hence applying traction to the guide catheter. It is our impression that the degree of guide catheter displacement is much less than that with a balloon and is more easily controlled.

Because of their proximal location within the vessel, coronary ostial lesions necessarily jeopardise a large proportion of the myocardium. Chest pain and the haemodynamic consequences of interruption of flow during balloon inflation can limit the duration of inflations. As the laser fibre is only applied to the lesion during the three second bursts used, its passage may be better tolerated than balloon inflation. One of our patients toleraied the passage of a $2 \mathrm{~mm}$ fibre without difficulty but was severely compromised on inflation of a balloon.

As our experience with the laser system has increased we have come to prefer Amplatz type guiding catheters over the Judkins type because the "line of attack" on the lesion can be $\underline{\underline{T}}$ varied by advancing or withdrawing the cath- $I$ eter thereby altering the angle at its tip. This technique is especially important if an adequate $\stackrel{7}{c}$ result is to be achieved for ostial lesions with excimer laser angioplasty alone. We prefer $\stackrel{0}{\rightarrow}$ sidehole catheters because they reduce the effects of impaction on coronary flow.

A further potential advantage of excimer laser angioplasty arises from its mechanism of lesion remodelling, thought to be achieved by क photochemical ablation. ${ }^{12}$ If ostial lesions do $\overrightarrow{0}$ have an atypical composition that contributes to procedural failure, complications, and restenosis, tissue ablation rather than compaction may lead to improved results.

Conflicting preliminary results from the use of directional atherectomy for ostial lesions in have recently been reported. ${ }^{13}{ }^{14}$ In the larger of $\mathcal{~}$ the two series this technique was associated $\mathrm{O}$ with a poor success rate and a high level of complications.

Our results, obtained in a group of high risk patients, compare favourably with those obtained by Topol et al in a low risk group. We achieved higher rates for both angiographic and long term success and lower rates for both clinical recurrence and restenosis. ${ }^{2}$ The only procedure related death was a consequence of laser angioplasty to a second lesion in the left anterior descending artery and not due to that on the graft ostial lesion which had proceeded successfully and uneventfully. The late death within the group occurred in a patient in whom the vein graft was the sole remaining coronary conduit. We presume that this graft became occluded. Both patients were at very high risk because they had had two previous bypass procedures, thus presented with severe symptoms, and they were not suitable for more surgery.

Until recently the scope of excimer laser angioplasty as a stand alone procedure has been $\frac{D}{0}$ limited by fibre diameter ${ }^{15}$; however, the availability of the $2 \mathrm{~mm}$ laser fibre has increased o the attainable lumen diameter and enabled us $N$ to treat successfully seven patients without N balloon supplementation. Two of our patients with vein graft ostial lesions required balloon supplementation but the recent introduction of a $2.2 \mathrm{~mm}$ laser fibre may avoid the need for this. ?

These results are promising but it must be 0 remembered that we treated a more heterogeneous group than Topol et al. ${ }^{2}$ This limits the $\stackrel{\square}{\square}$ value of a direct comparison of their results $\mathbb{Q}$ with ours. It might have been expected, however, that our high risk patients would fare 8 worse than their low risk group. Also our study group is not large. Clearly there is a need for further experience with excimer laser angioplasty for ostial stenoses, especially where they are solitary lesions.

We are grateful to Ted Fuller for his skilled technical assistance. 
1 Mathias D, Fishman Mooney J, Lange H, et al Frequency of success and complications of coronary angioplasty of a
stenosis at the ostium of a branch vessel. $\mathrm{Am} \mathrm{J} \mathrm{Cardiol}$ stenosis at the

2 Topol E, Ellis S, Fishman J, et al. Multicentre study of percutaneous transluminal angioplasty for coronary artery ostial stenosis. J Am Coll Cardiol 1987,9.1214-8.

3 Thompson R. Coronary ostial stenosis in women. $\mathrm{J} \mathrm{Am} \mathrm{Coll}$ Cardiol 1986;7:997-1003.

4 Eigler N. Results of excimer laser angioplasty. In: Litvack F, ed. Coronary laser angioplasty. Oxford: Blackwell Scientific Publications, 1992:85-97.

5 Eigler N. Technique and patient selection for excimer laser angioplasty. In: Litvack F, ed. Coronary laser angioplasty. Oxford: Blackwell Scientific publications, 1992:72-84.

6 Myler R, Stertzer S, Cumberland D, Webb J, Shaw R. coronary angioplasty; indications, contraindications and coronary angioplasty; indications, contraindical
limitations. J Interven Cardiol 1989;2:179-85.

7 Tierstein P, Stratienko A, Schatz R. Coronary stenting for ostial stenosis: initial results and six month follow-up. Circulation 1991;84 (supplement II):250.

8 Rissanen V. Occurrence of coronary ostial stenosis in a necropsy series of myocardial infarction, sudden death, and violent death. Br Heart $J$ 1975;37:182-91.

9 Baucek R, Takashita R, Brady A. Microanatomy and intramural physical forces within the coronary arteries. Anat Rec 1965;153:233-41.

10 Saltissi S, Webb-Peploe M, Coltart D. Effect of variation in coronary artery anatomy on distribution of stenotic lesions. Br Heart J 1979;42:186-91.

11 Webb-Peploe $M$. Excimer laser coronary angioplasty: initial experience at St Thomas' Hospital. Laser Med Sci $1991 ; 6: 339-47$.

12 Isner J, Donaldson R, Deckelbaum L, et al. The excimer laser: light microscopic and ultrastructural analysis of potential advantages for use in laser therapy of cardiovascular disease. J Am Coll Cardiol 1985;6:1102-9.

13 Garratt $\mathrm{K}$, Bell $M$, Berger P, Bresnahan J, Higano S Directional coronary atherectomy of saphenous vein ostial lesions. Circulation 1991;84 (suppl II):26.

14 Robertson G, Simpson J, Vetter J, et al. Directional coronary atherectomy for ostial lesions. Circulation 1991;84 (suppl II):251

15 Sanborn T. Early limitations of coronary excimer laser angioplasty. J Am Coll Cardiol 1991;17:995-6. 